\title{
OPTIMISATION OF THE RESOURCE ECONOMY OF METALS, MINERALS AND ENERGY IN AN INTERPLANETARY PERSPECTIVE
}

\author{
Jan Stenis \\ William Hogland \\ Linnaeus University, Sweden
}

\begin{abstract}
Valuable metals and minerals are becoming ever scarcer on Earth. The global population is steadily increasing. Thus, new sources of natural resources in space are now needed as an alternative to digging deeper into Earth. Therefore, a cost structure is proposed for generally improving the resource economy of metal and mineral commodities and energy resources based on the optimisation of residuals as regards resource exploitation on primarily an interplanetary scale. The introduced methodology involves business administration and economics theory and employs the previously introduced equality principle and the Efficient Use of Resources for Optimal Production Economy (EUROPE) model. The suggested theory is applicable in the solar system and the space-platform context. A case study shows how to in practice apply the findings on the USA exploiting natural and energy resources on asteroids and the red planet Mars. It is concluded that the presented methodology is useful for increasing the cost-effectiveness of mainly the occurring residuals when exploiting natural and energy resources and commodities outside of our own planet in space. Also, the equity of the distribution of such facilities is improved on all scales. The developed methods are suitable information support tools for decision-making in the management of natural resources, with emphasis on the economy of residuals on the interplanetary level as well as generally being applicable on ore mining. A proposed key figure enables management to immediately obtain an overall comprehension of the economic, technological and environmental performance of their interplanetary endeavours that hence continuously can be reviewed, monitored and evaluated.
\end{abstract}

\section{KEYWORDS}

Space economy; natural resources; business economics; economics; residuals; nations; solar system; space-platforms; the equality principle; the EUROPE model.

\section{INTRODUCTION}

Shortly after the last ice age that ended some 11,500 years ago, there were few living humans as also have been the case when super volcanos occasionally have erupted [1]. 65 million years ago 
almost all land-living creatures were extinct, probably due to a major asteroid impact. Strictly statistically, a similar hit will soon occur again [2].

Earth was shaped from the accretion disc of the sun approximately 4.5 billion years ago [3]. Universe has been a most dangerous place for its inhabitants since it emerged some 15 billion years ago [4]. Currently, all our eggs are in one basket like the dinosaurs before the extinction. If we humans do not move out into space and all environmental things go wrong, we will be just as extinct [5]. Moving out into space gives a better guarantee for the human race to survive in the long term perspective. Here on Earth, the space age for living creatures commenced when the Russian dog Laika orbited Earth in 1957.

The technological development gained a major momentum with the start of the industrialisation in Great Britain in the 1750s [6] and the subsequent search for new markets to exploit in the new world and the overseas colonies [7]. 300 years after these often violent events, space is expected to be colonised [5].

The People's Republic of China manned spaceflight program began in the 2000s. The European Union, Japan, and India also plan future manned space missions. During the 21st century, China, Russia, Japan, and India intend to conduct manned missions to the Moon, while the European Union plan to go to both the Moon and Mars. In the 1990s, the promotion of private space tourism began. Then private space exploration of the Moon was promoted [8] [9] [10].

As a result, a new economic geography of money and finance in space emerges. The momentous changes that take place in the world's financial systems particularly have impact on globalisation, deregulation, privatisation and technological change [11].

The employed term space economy denotes the full range of activities and use of resources that create and provide value and benefits to human beings when exploring, understanding and utilizing space. The "space economy" was estimated at about $\$ 251$ billion in 2007 . More than 60 percent of the space-related economic activity came from commercial goods and services [12]. Here, the term "space economy" is applied to generally describe and encapsulate the phenomenon of financial transactions of all kinds related to different, commercial interplanetary activities in cosmos outside Earth.

The world's population will grow to 9 billion over the next 50 years [13]. This development imposes a possible need for new habitats outside our home planet to meet the increasing need for land to settle in for mankind. The findings in this paper promote the ambition to expand man's potential dwelling-places by facilitating the exploitation of distant worlds in cosmos.

No one knows with absolute certainty if a future deficit of metal and mineral commodities occurs [14]. Man does not know in detail how the ecosystems functions and how their elements are composed which complicates the design of remedies [15]. The crucial issue is how much confidence one can have in technology. Therefore, the debate continues [14]. Efforts to optimize the production and the use of commodities also in space are hence beneficial.

Therefore, the interest in space is not just scientific, it is also commercial. Exploitation of the resources of space could solve Earth's three major fulfilment problems: energy, mineral resources and food including water. The atmosphere of Mars could chemically be broken down to obtain 
substances that can be used as spacecraft propellants. Asteroids could be hollowed out to transform them into liveable habitats and could be mined for precious metals to be used in space construction projects. Also the comets and the moons of Mars could be suppliers of water. Helium could be extracted from moon rocks and radioactive minerals from asteroids could be used as fuel in fusion reactors [16].

It should be noticed that habitable stone planets rich on metals and minerals exist only within a certain sector around a star. To close to the current star it is too hot and far away one finds cold gas giants like Saturn and Uranus. Also, the planet's sun must be stable in size and energy output and the planet's orbit must be close to circular so that the seasons are similar. The planet's atmosphere must provide oxygen, carbon and water and must also be transparent to certain radiation types but opaque to others. Seeing animals are well adapted to the Earth's atmosphere [17].

Near-Earth asteroids and comets may be economical sources of raw materials for large space construction projects. It should be rather easy to move such objects within range of space-based industrial operations. Asteroids are rich in the metals and minerals that are necessary to build space facilities while comets provide the water and carbon-based molecules needed to maintain life [18].

Tens of thousands of meteorites have been collected and studied in detail. Planetary scientists therefore know what asteroids are made of and that they contain valuable metals also from telescopic observations and taking spectra of asteroids. Radars tell about the properties of objects that come very close to Earth. All studies point in the direction of these resources being abundant in space. Such mineral deposits are very promising due to familiar experiences on Earth where geochemical processes produce small but highly concentrated ore deposits in the Earth's crust. Asteroids are namely mostly undifferentiated bodies that lack separation into core, mantle and crust. Thus, there is no need to seek out mineral deposits because the entire asteroid is an ore [19].

The near Earth asteroids are primary targets to get resources for supporting the upcoming industrialization of space [20]. Materials that could be mined or extracted include iron, nickel, and titanium suitable for construction purposes, water and oxygen to sustain the lives of prospecting astronauts on site and hydrogen and oxygen to be used as rocket fuel. Metallic asteroids mainly consist of pure nickel-iron alloy. Such asteroids also contain several hundred parts per million of gold and platinum-group metals (PGMs) [19]. It has been estimated that a 30-meter long asteroid can hold as much as $\$ 25$ billion to $\$ 50$ billion worth of platinum at the current prices [21]. The right 80 -meter asteroid would have more than $\$ 100$ billion worth of commercial materials. A single metallic asteroid only $200 \mathrm{~m}$ across could be worth $\$ 30$ billion at today's prices. A single 500-meter asteroid with a high concentration of platinum would contain the equivalent of all the PGMs ever mined on Earth [22]. The PGM material is valuable not just because it is scarce here on Earth but because it is a very useful element. It has good catalytic properties and is used for high-temperature crucibles etcetera [19]. The annual worth of the obtained resources for use on Earth and beyond is estimated to tens of billions of dollars' when mining asteroids [22]. Enriched ore from asteroids can be transported in very large cargo ships to Earth. Due to the low gravity in space, no heavy construction is required to encapsulate the commodities that are transported. In the future, teleportation represents an alternative to traditional cargo ships as a substantially more efficient mean of transportation in space [23]. 
There are millions of asteroids in the main asteroid belt between Mars and Jupiter. There are perhaps a million more near-Earth asteroids that have drifted from this belt and assumed stable solar orbits closer to us [24]. Nearly 9,000 near-Earth asteroids are known today and more than 1,500 of them are considered to be easier to reach than the surface of the moon [25]. Legendary Russian rocketeer Konstantin Tsiokolvsky first articulated the concept of mining asteroids in 1903 [24].

Studies of similar kind features, for example, an economic simulation model to bring down costs for a global organization focused on space infrastructure and economic expansion in order to plan, coordinate, fund and implement infrastructure construction [26]. However, no model seems to have been developed to by a single key factor simultaneously manage and optimize the economy, the technology and the environmental conditions of outer space being the main feature of this study.

Note that an efficient usage of resources and an efficient waste handling and recovery is a necessity also in space. Thereby the major goal is not to minimize wastes but to optimize the resource economy in order to transform as much of the input to products that profitably can be sold on the markets of all geographical levels. In doing so, a win-win situation is achieved since less residuals produced improves the resource economy which increases the profitability that in turn give more financial resources to invest in more efficient machinery that causes less wastes and so on.

One may claim that one can neglect wastes in the vast cosmos and that matter and energy exist in abundance if the right technology is available. However, the competition on the (interstellar) market will always force a need for an ever improved resource economy to raise the desired profits. Thus, the need to use the natural resources efficiently will always prevail and the first author's own EUROPE model will hence always be needed to optimize the production processes.

Besides, the continuing growth in space debris poses an increasing threat to, for example, satellites in economically vital orbital regions [8]. Waste management will hence be important also when man expands his geographical limits. In space, all equipment namely must be designed in a lean way and operate efficiently due to the limited room that one must work in in the surrounding vacuum. Therefore, wasting of all kinds must be avoided also in space.

The EUROPE model have shown to be applicable on, for example, mechanical workshops [27], bulk industry [27], construction [28], landfilling [29], waste baling plants [30], ore mining [31] and landfill mining (in press). The EUROPE model is based on the generic black box concept and can be employed as soon as a production process takes place. This eon-old transformation of resources into goods will continue as long as life in any form exists. Thus, the concept advocated here is possible to apply on the exploitation of natural resources throughout space many thousand years in the future when man probably lives on platforms orbiting the planets and perhaps travels through cosmos as the common nomads in the history of mankind in order to colonize distant worlds. Mankind is hence likely to bring their administrative system of the past based on nomads and groups of people when man will establish dwellings between the planets in distant sun systems. Thereby, the work on the surface of the planets and the perhaps captured asteroids and comets is likely to be performed by remotely controlled or autonomous robots [32]. Turning a captured asteroid into an efficient Earth-shield appears to be quicker, easier, cheaper and safer than landing on an incoming impact-bound asteroid for altering its trajectory or destroying it [33]. 
Thus, the term nation will probably not be very relevant anymore when space is explored. Instead, it is more relevant to use the term administrative unit to denote the entity in question that is the object of study in order to optimize the resource economy. It should be noted that as the technological level increases, the supply of material and energy sources is likely to be ever more abundant and will not constitute a limitation to human or robotic activities. At this stage, the present currency system might be replaced with a system for remuneration based on altruism to enable payment with mentally based virtues such as good deeds and making people feeling well.

Therefore, the objective of this study is to provide basic methods that managers on the UN and OECD levels can use to obtain guidelines for how to increase the cost efficiency of mining activities and similar schemes within the planetary system by the employment of the EUROPE model [28] that is based on the equality principle [27] [28]. In doing so, the equity of the distribution of natural resources and commodities is promoted due to the optimization of production residuals throughout our interplanetary system.

However, it may be argued that the cosmic expansion might be hampered by the fictive but extra costs that are employed in this study. This could possibly prolong the time before humans become independent of their home planet Tellus in order to avoid devastation due to a large meteorite impact and the like. In this context, it should be noted that the shadow costs that are allocated to unwanted phenomena in this study, are not really traditional costs or real burdens to the administrative units in question. No, they are rather a versatile tool to enable an efficient reviewing, monitoring and evaluation of how the optimization of the cosmic resource economy is progressing, the paramount objective being to promote the preservation of all the relevant knowledge and the diverse expressions of the civilisation of the humans or their successors in one form or the other.

\section{METHODOLOGY}

In this paper, a cost structure is proposed for throughout our interplanetary system optimising the exploitation of natural resources from a cost efficiency and equity point of view. The aspect of residual economy in relation to the exploration of space is emphasised. Thereby, the terms "bad" and "good" residual are here used in the traditional meaning even though a bad under certain circumstances could transform into a good. Thus, a break-even point could be defined for that.

Thereby, an introduction reviews the relevant history also in the geological context. Particularities of the exploitation of resources in cosmos are also explained. The previously introduced equality principle and the EUROPE model are applied in this context. Guidelines are presented for how to apply the methodology introduced for improving the cost efficiency of residuals on the exploitation of metal and mineral commodities and energy resources in an interplanetary and a space-platform context.

The survival of our species depends on the employed concepts for exploitation of minerals and energy in space including a fruitful sustainability discussion. In the future, this is a necessity in order to create a healthy economy throughout the planetary system. Therefore, the sustainability debate must be renewed and modern thinking, such as the novel concept introduced in the present paper, included. The framework of the conducted research should initially be limited to Earth's close surroundings in space since not being realistic to exploit other planet systems in the foreseeable future. Thus, the geographical limit of the work presented here is the solar system. 
The cosmic supply of energy to mankind is in this work assumed to not yet be unlimited. The technological development is hence assumed to not yet have reached the level of utilizing energy without limitations.

The proposed model assumes a situation where the burdens of the cosmic exploitation endeavour are carried by a number of different sub-units within the current comprising administrative entity such as our solar system. Thus, when for example all the people of Earth can be considered to be just one big family without any personal difference in colour, creed or class, there will not be any sub-units to allocate cost to in competition with other sub-units that neither want to carry any unjustified economic burdens. However, this situation will not be realized in the near future.

A discussion section reviews and comment upon the major findings. The substantial outcomes of the study are presented in a conclusions, benefits and recommendations section. Suggestions for further research are given.

The scientific methodology chosen combines the study of: (a) what should be changed and how, and; (b) the development of theories and models based on the accumulation of knowledge presented in, in this case, a scientific paper. The scientific approach is mainly analytic.

A quantitative methodology is mainly applied. The theory is exemplified through numerical examples from within the planetary system of the sun.

The validity of the developed methods is promoted by the application of commonly accepted traditional theory of economics based on scientific results and long experience of its practical usage. The reliability is ensured by using relevant standard works and peer-reviewed scientific papers as input to the present study.

\section{THE EUROPE MODEL BASED ON THE EQUALITY PRINCIPLE}

A new way of looking at the global distribution of wealth connected to the distribution of natural resources and commodities is needed. Otherwise, the long-run process of achieving planetary and interstellar equity and environmentally acceptable conditions may be slowed down.

The shift in paradigm that is argued for here involves equating residual products with regular products in terms of the allocation of revenues and costs. This approach is termed the equality principle [27] [28] and forms the basis for the forthcoming discussion. It represents a modernized sustainability-thinking in space, by time, throughout the entire known universe.

The residuals of the different studied natural resources are regarded as a regular output which is mathematically considered in Equation (1). This equation is used for the additional allocation of costs to a certain resource residual through multiplication by the total costs in question that as fictive costs are to be allocated by splitting them up in their proper proportions. 
$P F=A /(B+C)$

where

$P F=$ The Proportionality Factor that proportionally allocates costs (and revenues) to $A$ (2)

$A=$ A certain bad residual from a certain resource and/or commodity produced.

$B=$ The regular, good resource output and/or the regular product output of goods.

$C=$ Sum of all the different residual fractions produced, i.e. all the bads.

Sort: kilogram, litre, Joule or monetary value.

Equation (1) represents the economic implications of the equality principle and is termed the model for Efficient Use of Resources for Optimal Production Economy (EUROPE) [28]. Of course, when applying Equation (1), a suitable production or an administrative unit must be defined, depending on the circumstances, for example, a production line on a certain planet, a space-platform or an exploited asteroid.

Thus, shadow prices, or shadow costs, are obtained that induce strong economic incentives to reduce the unwanted residuals which these shadow costs are allocated to. If fully regarded, the financial statements that the relevant actors present, for example, will hence be affected in a way that optimizes the excessive occurrence of residuals and the failure to utilise it productively. Thus, the equality principle is an economic instrument.

It is important to notice that the shadow costs, which emerge when the EUROPE model is applied on a producing unit, do not exist in reality but are purely fictive. These shadow costs mainly serve the purpose of being a versatile tool for management to review, control and evaluate the producing activity in question but they are intended to exist just as a parallel book keeping system that does not at all affect, for example, the bottom lines in the traditional profit and loss account and balance sheet.

Thus, managers should use the EUROPE model mainly to increase the efficiency of the production apparatus by pin-pointing the residual phenomena that primarily must be reduced in an order of declining economic importance until the whole enterprise or project is optimized as regards its efficiency of its resource usage. Therefore, the use of shadow costs advocated here will in no way hamper the corporate will to expand in the short run since the traditional Venetian method of double-entry book keeping is separately maintained with the novel concept presented here serving as a back-up to improve the management function.

For economic reasons, the production apparatus of industry will hence be forced to become more efficient. Above all, the ratio of utilising the purchased material and the energy input will improve if the fictive shadow costs that occur when the equality principle is applied are fully considered. Thereby, both the economy, the technology used and the environment will improve due to less residual products being produced.

Also in the distant future, the EUROPE model will be possible to use successfully since it considers the universal production unit in the form of a black box with its connected input and output and the corresponding, minor outflow of usually unavoidable residuals. The black box concept is here considered to be eternally generic and the EUROPE model is hence likewise. 


\section{INTERPLANETARY ECONOMY THEORY}

\subsection{General remarks}

Below, the theory is outlined for how to apply the equality principle on different administrative levels, also in the cosmic context. Thereby, the paramount objective is to promote the long-run survival of the human race.

A situation is also considered when material and energy resources in the future are available in abundance. Therefore, the creatures living in the future can probably afford to be materially generous.

The developed theory is applicable on all geographical levels, all the way from a single machine in a workshop up to the whole planetary system. The comprising administrative entity that constitutes the basis for the calculations in the cosmic context hence can be as shown in Table 1 . Note that the theory developed here with due modifications is equally applicable in the robot, the Milky Way and the local galaxy cluster perspective.

Table 1. Comprising administrative entities in the cosmic context.

1. One or more exploiting nations on a certain planet;

2. One or more whole exploiting planets in a sun system;

3. One or more exploiting space-platforms in a star-fleet orbiting one or more exploited planets, asteroids or comets.

\subsection{Metal and mineral commodities}

The total cost for mining and excavation of all the natural resources goods within the planetary or space-platform based exploiting and comprising administrative unit is denoted TC.

Equation (1) gives:

$P F$ commodity $=A$ commodity $/(B$ commodity $+C$ commodity $)$

where

$A$ commodity $=$ A certain bad residual from the production of a certain commodity at a certain planet, asteroid and/or comet

$B$ commodity $=$ The regular planetary and/or space-platform based production goods of all the certain commodities

$C$ commodity $=$ All the related different planetary and/or space-platform based residual fraction bads produced 
within a suitable production facility or an administrative unit in space, for example, a production line on a certain planet, a space-platform or an asteroid, on an annual or other time limit basis.

Sort: kilogram, litre or monetary value.

$P F$ commodity is multiplied with $T C$ to obtain the shadow cost to additionally allocate to different units' government budgets within a certain comprising administrative unit. This multiplication is done in proportion to all of the units' budgets for exploitation of natural resources. This item is denoted REXOF commodity where REXOF is short for the term Resource EXploitation Optimisation Fee or a fictive extra exploitation cost in spite of the term fee being more rational to use.

REXOF commodity $=$ Shadow cost allocated to $A$ commodity $=P F$ commodity $* T C(10)$

REXOF commodity $j$, the part of REXOF commodity to as a shadow cost additionally allocate to a certain administrative unit's government budget, i.e. unit $j$, is given by Equation (11).

REXOF commodity $j=R E X O F$ commodity $* C O E C j / C O E C$ total commodity

where

COEC $j=$ COmmodity Exploitation Cost of administrative unit $j$

COEC total commodity $=\sum C O E C j$

$i=1,2, \ldots$, planetary and/or space-platform based commodity

$j=1,2, \ldots, n$

exploiting comprising administrative unit $j$

Sort: kilogram, litre or monetary value.

\subsection{Energy resources}

The total cost for mining and excavation of all the natural resources goods within the planetary or space-platform based exploiting and comprising administrative unit is denoted $T C$.

Equation (1) gives:

$P F$ energy $=A$ energy $/(B$ energy $+C$ energy $)$

where

$A$ energy $=$ A certain spillage bad from the production of a certain energy resource at a certain planet, asteroid and/or comet

$B$ energy $=$ The regular, planetary and/or space-platform based production goods of all the certain energy resources 
$C$ energy $=$ All the bad spillages of the planetary and/or space-platform based energy production and utilization

within a suitable production or administrative unit on an annual or other time limit basis.

Sort: Joule or monetary value.

$P F$ energy is multiplied with $T C$ to obtain the shadow cost to additionally allocate to different administrative units' government budgets within a certain comprising administrative unit in proportion to all of the units' budgets for exploitation of energy resources. This item is denoted REXOF energy.

$R E X O F$ energy $=$ Shadow cost allocated to $A$ energy $=P F$ energy $* T C$

$R E X O F$ energy $j$, the part of $R E X O F$ energy to as a shadow cost additionally allocate to a certain unit's government budget, i.e. unit $j$, is given by Equation (19).

$R E X O F$ energy $j=R E X O F$ energy $* E N E C j / E N E C$ total energy

where

$E N E C j=$ ENergy Exploitation Cost of administrative unit $j$

ENEC total energy $=\sum E N E C j$ $i=1,2, \ldots$, planetary and/or space-station based energy exploiting

$j=1,2, \ldots, n$ comprising administrative unit $j$

Sort: kilogram, litre or monetary value.

\subsection{Multiple exploitation objects}

Weights $(W)$ can be conferred to different space objects of interest when exploited according to management's or the current authorities' preferences. $W$ is allocated to the object in question in relation to its relative importance compared to the other objects of the same kind within the current system limit. In the case of $n$ exploiting nations on a planet, $n$ exploiting sun system's planets and/or $n$ exploiting space-platforms, the Total Resource EXploitation Optimisation Fee (TREXOF) can be calculated as follows:

$$
\begin{aligned}
\text { TREXOF }= & \sum(R E X O F j * W j) \\
& i=1,2, \ldots, \text { exploiting entity } j
\end{aligned}
$$

where:

TREXOF = Total Resource EXploitation Optimisation Fee for the $n$ exploiting entities to optimize 
REXOF $j=$ Resource EXploitation Optimisation Fee for the exploiting entity $j$ calculated employing equation (11) and (19) involving shadow prices

$W j=$ The weight conferred to nation $j$ on a certain planet, planet $j$ in a certain sun system and/or space-platform $j$ in a star-fleet respectively (sort less)

$j=1,2, \ldots, n$

within a suitable production or administrative unit on an annual or other time limit basis.

Sort: kilogram, litre, Joule or monetary value.

Equation (22) can be used for management or the authorities to obtain an overall comprehension of the incremental improvement of a certain space object operation. By applying Equation (22) on the entire set-up of different exploiting entities at a time, one gets a tool that enables an immediate flash-light review, monitoring and continuous evaluation of the on-going space exploration activities.

\subsection{Summarized theory}

Summarized, the theoretical findings of this study can be collocated in the general Equation (26) for the $m$ exploited resources and/or commodities by the $n$ exploiting nations, planets and/or space platforms.

SEXOF = Summarizing EXploitation Optimisation Fee for the $m$ exploited goods and the $n$ exploiting entities to optimize $=$

$\sum \sum((A x /(B x+C x)) * T C *(E C j l / E C$ total $) * W j l)$

$i=1,2, \ldots$, exploiting entity $j k=1,2, \ldots$, exploited resource and/or commodity $l$

where

$A \mathrm{x}=$ A certain residual bad from a certain resource and/or commodity $l$

$B \mathrm{x}=$ The regular production of all the $m$ related resources and/or commodities goods

$C \mathrm{x}=$ All the related different residual bad fractions or energy spillages produced

$T C=$ Total cost for mining and excavation of the $l$ resources and commodities within

the planetary or space platform based comprising administrative unit

$E C j l=$ Exploitation Cost for nation $j$, planet $j$ and

/or space platform $j$ when exploiting resource and/or commodity $l$

$E C$ total $=$ The exploitation cost conferred to the $n$ exploiting nations, space

- platforms and/or planets

$W j l=$ The weight conferred to nation $j$ on a certain planet, planet $j$ in a certain sun system and/or space platform $j$ in a star fleet when exploiting resource and/ 
$x=$

or commodity $l$ (sort less)

Interplanetary commodity, space - platform commodity, inter -

planetary energy resource and/or, space - platform energy resource respectively

$j=1,2, \ldots, n$

$l=1,2, \ldots, m$

within a suitable production or administrative unit on an annual or other time limit basis.

Sort: kilogram, litre, Joule or monetary value.

Equation (26) is useful for throughout the solar system simultaneously optimize the resource economy, the technology used and the environmental conditions when undertaking projects for exploitation of all kinds of commodities, material as well as immaterial. Thereby, less incentive-creating shadow costs allocated to a certain exploiting entity implies a more efficient handling of the fraction(s) in question since it then represents less disadvantageous but fictive costs that occur when applying the EUROPE model. Equation (26) hence constitutes a versatile tool for managing, measuring and evaluating all kinds of physically exploiting character throughout the planetary system of the sun.

In Table 2 different possible meanings of the terms and factors in Equation (26) are shown for an increasing geographical magnitude in space. The $S E X O F$ is to be understood as any shadow cost that depending on the circumstances should be allocated to the general residual $A$ that is to be optimized within a suitable production or administrative unit. In doing so the emerging but fictive shadow cost affects, for example, the current contribution margin of a certain product from a factory or the public sector borrowing requirement (PSBR) of a nation.

\subsection{Consequences of the space-economy theory}

The REXOF factor, the TREXOF factor and the SEXOF factor will force the nations, the planets and the space-platform fleets of interest to utilise the material resources and the energy resources in question within the sun system and the star-fleet in question in a more cost-effective way due to the economic incentives that are induced by an unfavourable increase in the final public sector borrowing requirement (PSBR) of the administrative entity in question. Thereby, the most costly national exploitation programmes in relative terms are most negatively affected by the employed shadow costs.

And the more of the REXOF, TREXOF and/or the SEXOF that is allocated to a certain nation, planet and/or space-platform, the less cost-effective is that nation's, planet's and/or space-platform's exploitation of the total natural resources and its usage of the total energy resources in relative terms and the more economic incentive is imposed on that nation, that whole planet and/or that space-platform to become more cost-effective and produce less mining and excavation and energy related final residuals throughout the sun system and/or the star-fleet in question. Note that in the future, the term "nation" could denote a number of space-platforms.

The technological level will be raised throughout cosmos due to the economic incentives that stems from the occurring shadow costs. Managers on all levels will namely put pressure on their 
colleagues that are responsible for the technological development to improve the efficiency of the current production apparatus. Otherwise the fictive but useful shadow costs will become too substantial when the proposed equality principle is applied in this context.

Also, the environment will be improved in space. The total environmental degradation stemming from produced residuals will namely decrease throughout cosmos due to the economic incentives to reduce the existence of residuals that occur when the equality principle is applied.

Table 2. Collocated theory for application of the equality principle on different geographical levels with illustrative examples in an increasing size based on the summarizing Equation (26).

\begin{tabular}{|c|c|c|c|c|c|c|}
\hline Level / Term & $A$ & $B$ & $C$ & $T C$ & $E C$ & $E C$ total \\
\hline Single machine & Cuttings & Products & All wastes & $\mathrm{FC}, \mathrm{VC}$ & Lathe $j$ & $\mathrm{n}$ assemblies \\
\hline Production line & Cuttings & Products & All wastes & $\mathrm{FC}, \mathrm{VC}$ & \multicolumn{2}{|c|}{ Assembly $j$ n work shops } \\
\hline Factory & Cuttings & Products & All wastes & FC, VC & \multicolumn{2}{|c|}{ Work shop $j \mathrm{n}$ factories } \\
\hline Nation & Residual & s Products & All wastes & Expense & \multicolumn{2}{|c|}{ Country $j$ n countries } \\
\hline Planet & Residual & s Products & All wastes & Expense & Tellus & Solar system \\
\hline Space station & Residual & s Products & All wastes & Expense & Platforı & j Star-fleet \\
\hline
\end{tabular}

Legend:

FC $=$ Fixed Costs

$\mathrm{VC}=$ Variable Costs

Expense or expenditure $=$ an outflow of money to another person or group to pay for an item or service

\section{CASE STUDY: THE USA EXPLOITS AN ASTEROID AND THE RED PLANET MARS}

\subsection{General remarks}

The proposed methodology is applied on the USA exploiting the natural and energy resources on an asteroid and the red planet Mars respectively as a case with data from the real world. The USA is chosen as the study object since it is a well-known actor in space-travel and because economic data from USA is easily available. The comprising administrative unit in the case study is the solar system. The example shows the general applicability of the theory. In a similar way it can be applied on exploiting planets, robots, space-platforms and whole galaxies in the case of creatures from the Milky Way exploiting, for example, the Andromeda galaxy. 
The general idea is that shadow costs for the residual tellurium when the USA exploits platinum on an asteroid and the shadow costs for the energy spillage when the USA exploits uranium on Mars is allocated to a certain nation (USA) on Earth in proportion to that nation's part of the total, global cost for exploitation of our solar system in relation to all the nations on Earth performing space exploration. Shadow costs can also be allocated to one or more space-platforms when a certain fleet of such platforms exploits a number of planets or asteroids of commercial interest. The important thing is to know how big part of the total shadow cost for a phenomenon to be optimized that a certain, exploiting unit should carry in order to obtain a tool for reviewing, monitoring and evaluation of the on-going exploitation activities in terms of the technological efficiency, the profitability and the impact on the surrounding environment that simultaneously hence are optimized by the proposed model that is based on the equality principle invented by the first author.

\subsection{Metal and mineral commodities}

The total global cost (TC) for mining and excavation of all the natural resources within the solar system outside Earth is assumed to be $\$ 100$ billion. According to the OECD statistics, the gross domestic product (GDP) of the USA for industry, including energy, during recent years amounts to approximately $\$ 2$ trillion [34]. Five per cent that is to say $\$ 100$ billion of this national industrial output seems to be a reasonable amount to initially allocate to cosmic industry costs for the whole Earth. Half of the approximate GDP for industry, including energy in the USA that is to say $\$ 1$ trillion is regarded to be a reasonable amount for the future global production of goods within the solar system outside Earth, here denoted $B$ commodity. A total estimated cost for a mission to mine an asteroid of $\$ 5$ billion is almost certainly low [35]. The $A$ commodity value of the tellurium residuals in the case study is assumed to constitute a fifth that is to say $\$ 1$ billion of this estimated, low cost for mining an asteroid. The total value of the residuals produced within the solar system outside Earth is set to ten times that value that is to say $\$ 10$ billion, here denoted $C$ commodity. The annual total global cost for exploiting commodities within the solar system outside Earth is estimated to amount to five times that value that is to say $\$ 50$ billion, here denoted COEC total commodity. The corresponding cost of the USA is set to half that sum that is to say $\$ 25$ billion, here denoted COEC USA. The values of the case study in 5.3 for energy resources are allocated in a similar way. Thus, the employed values in the case study are grossly rounded so to just show the general applicability and realism of the proposed optimizing theory.

Equation (1) gives:

$P F$ commodity $=A$ commodity $/(B$ commodity $+C$ commodity $)=0.1 \%$

where

$A$ commodity $=$ Value of the residual tellurium when producing platinum at an asteroid $=$ \$1 billion Compare Equation (7)

$B$ commodity $=\$ 1$ trillion $\quad$ Compare Equation (8)

$C$ commodity $=\$ 10$ billion $\quad$ Compare Equation (9) 
within the solar system on an annual basis.

$P F$ commodity is multiplied with $T C$ to obtain the shadow cost to additionally allocate to USA's government budget in proportion to USA's budget for exploitation of natural resources within the solar system in relation to the total global budget for exploitation of natural resources within the solar system. This item is denoted REXOF commodity USA.

REXOF commodity $=\$ 100$ million $\quad$ Compare Equation (10)

REXOF commodity USA, the part of REXOF commodity to as a shadow cost additionally allocate to USA's government budget, i.e. unit $j$, is given by Equation (40)

REXOF commodity USA $=$ REXOF commodity $*$ COEC USA / COEC total commodity $=$ $\$ 50$ million

where

COEC USA $=$ COmmodity Exploitation Cost of USA within the solar system $=\$ 25$ billion

COEC total commodity $=\sum$ COEC $j=\$ 50$ billion

$i=1,2, \ldots$, planetary and/or space platform based cost of

$j=1,2, \ldots, n$ commodity exploiting Earth nation $j$ within the solar system

\subsection{Energy resources}

The total cost for mining and excavation of all the natural resources within the solar system is assumed to be USD 100 billion and is denoted TC. Uranium is a basis for producing nuclear fuel.

Equation (1) gives:

$P F$ energy $=A$ energy $/(B$ energy $+C$ energy $)=0.1 \%$

where

$A$ energy $=$ Value of the energy spillage when producing uranium at Mars $=\$ 500$ million Compare Equation (15)

$B$ energy $=\$ 500$ billion $\quad$ Compare Equation (16)

$C$ energy $=\$ 5$ billion $\quad$ Compare Equation (17)

within the solar system on an annual basis.

$P F$ energy is multiplied with $T C$ to obtain the shadow cost to additionally allocate to USA's government budget in proportion to USA's budget for exploitation of energy resources within the solar system in relation to the total global budget for exploitation of energy resources within the 
solar system. This item is denoted REXOF energy USA.

$R E X O F$ energy $=\$ 100$ million $\quad$ Compare Equation (18)

REXOF energy USA, the part of $R E X O F$ energy to as a shadow cost additionally allocate to USA's government budget, i.e. unit $j$, is given by Equation (48).

REXOF energy USA $=$ REXOF energy $*$ ENEC USA $/ E N E C$ total energy $=\$ 50$ million

where

ENEC USA $=$ ENergy Exploitation Cost of USA within the solar system $=\$ 25$ billion

ENEC total energy $=\sum E N E C j=\$ 50$ billion

$i=1,2, \ldots$, planetary and/or space station based energy exploiting Earth nation $j$ within the solar system

$j=1,2, \ldots, n$

\section{DISCUSSION}

The present paper shows how the equality principle for equating residuals with regular products in economic terms can be applied to traditional economics theory in an interplanetary as well as the global perspective by the use of a uniform methodology that works equally well when applied on everything from the output from a single machine in a production line in a factory to exploitation of commodities across the whole galaxy cluster. However, the system limit and a suitable calculation-unit must be set. This somewhat generic approach is here shown to enable a financially sound basis for environmentally friendly management of exploitation of natural and energy resources throughout cosmos in order to secure the long run survival of mankind.

The developed theory shows the principle of corporate-internal shadow prices being applied on the planetary and the star-fleet levels. The overall goal of the study was to investigate the possibility of adapting the proposed methods invented by the first author in a cosmic context.

The applicability and realism of such methods is indicated by the developed expressions for how to estimate the REXOF, TREXOF and SEXOF values of the residuals in question. The illustrative case study produces a reasonable REXOF commodity USA and a likewise reasonable $R E X O F$ energy USA of $\$ 50$ million respectively that as purely fictive but incentive-increasing shadow costs are intended to be additionally added to the public sector borrowing requirement (PSBR) of the USA. In doing so the resource economy can be improved in the exploitation of platinum on an asteroid and uranium on the red planet Mars.

Thus, there appears to be no specific obstacles to applying the proposed methodology to the space industry. The methodology suggested can be assumed, therefore, to be generally applicable to all activities that are related to the exploitation of commodities where residuals are produced.

The paper shows how the principle of in economic terms equating industrial waste with normal 
products - the equality principle - can be combined with traditional economics methods so as to provide a financially sound basic theory for the management of resource exploitation in space. The developed equations show the possibility to apply this principle according to the proposed EUROPE equation (1) to the governmental budgets which produces a substantial negative impact on the exploiting nations', planets' and space-platforms' budgets by increasing, for example, the national PSBR. This is due to the corporate-internal shadow costs associated with residuals and the shadow costs that subsequently are assigned to the corresponding exploiting objects.

Environmental impact weights are elaborated upon and declared possible to be combined with the mathematical principle for estimation of the REXOF, TREXOF and SEXOF values. The proposed general equations (22) and (26) illustrate the logical consequences of in a summarizing way applying the equality principle in the macroeconomic scale on all possible geographical levels and time-perspectives.

One may argue that the transfer of costs from the "goods" to the "bads" is somewhat distorted. However, no known estimation method yields results that are completely valid.

A direct link exists in the present study between economic losses and the existence of residuals by, for example, cost redistribution and weighting of the impact of the different exploiting entities and the exploited resources and/or commodities. Thus, economic pressure is exerted to introduce measures that reduce waste at the source. Thereby, also the production efficiency is enhanced.

This reduces both the production of residuals and the distortion that occur in the cost allocation. The distortion becomes less when the co-ordination increases as regards accounting principles for a steadily enlarged geographical area in which the suggested approach is employed. A trade-off hence takes place between economic exactness and technological and environmental benefits.

The main purpose of applying the equality principle is not to maximize company and other kind of profits, but rather to improve the probability for our species to survive, as one form of life or the other. Experience shows that, in the long run, conservation of natural conditions and maximization of profits tends to be consistent with one another.

The approach described here is not considered as being limited to the current phenomena described in this study. The methodology is suggested to be applicable to any industrial activity producing solid or energy wastes provided that the presently known laws of nature are valid.

The results presented here will promote the acceptance of a novel way of regarding waste from a space-economic perspective and encourage the development of alternatives to traditional taxation practices, the aim being to increase the economic incentives to optimize the resource economy by reducing industrial waste and changing the attitudes towards it. It is hoped that this study will promote a change in the perceived status of most residuals in general through emphasizing the financial impact of shadow prices on the expenditures and receipts of governmental budgets at different administrational levels.

Budgetary costs are hence linked to the production of residuals in terms of the redistribution of costs between regular products and residuals. In doing so, economic pressure is exerted on nations, planets and space-platforms to introduce effective measures to promote reduction of 
wastes at the source. Thereby, also the production efficiency and the profitability are enhanced. For example, forecasts, budgets and receipt and expenditures accounts for external use that governments present affect the excessive occurrence of residuals and the failure to utilise it productively in a strictly financially encouraging way. Appropriate official recommendations and voluntary environmental agreements for assessing industrial wastes are needed. This may be required to force cosmic entities to improve the sustainability and productivity of resource use.

The study will change the perceived status of, for example, mining waste through the financial implications of the use of shadow prices in the developed theory on expenditures and receipts. Hopefully, the basic approach of this study will be adopted by the interstellar authorities of the future, accompanied by a paradigmatic shift towards long-term sustainable production regarding the perception of residuals.

Residuals which are unavoidably produced can be reduced and utilized in better ways. Then, a substantial contribution can be made to the waste-reducing ambitions of central authorities, the overall goal being the achievement of the long-run survival of Homo sapiens or their successors such as the robots.

The general approach of the proposed methodology here employs economic theory as an umbrella-solution based on mathematics. This is a strength that makes the application of the model independent of, for example, technological parameters and fluctuating ambitions to modify the physical surroundings since such phenomena here are expressed in purely monetary terms.

A weight factor approach is introduced. It is intended to promote ambitions related to, for example, environmental policy. However, the major feature of the model is the anticipated industrial and environmental changes and redistribution of wealth in a global context through expressing most factors of reality in encapsulating monetary terms.

As another important feature, management obtain a corporate-internal and flexible tool to at the same time optimize, monitor and evaluate the performance of their mining or energy project. This is accomplished by reducing the existence of non-profitable fractions by providing economic incentives to mainly excavating the matter of commercial interest, fraction by fraction in order of declining economic relevance. Continuous study of the development of the overall shadow cost enables the general performance of the current project to be followed and immediately obtained through the key figure provided by Equation (26).

The somewhat less good precision concerning which actors that are and should be affected most when the proposed theory is implemented is a minor weakness of the work. The precision in the calculations when the methodology is applied can never the less be improved by, for example, auxiliary algorithms that may be developed and integrated with the EUROPE model to improve the current methodology.

The introduced approach will influence the distribution of wealth throughout cosmos. When applied, the invented tool will reshuffle revenues and profits from mining activities and the like through increasing the efficiency where most needed. The administrative entities showing the least cost-effective mining and energy-utilisation industry will encounter the heaviest disadvantages enforced by suitable cosmic actors to improve the utilisation of their assets. Thus, these less efficient entities are likely to over time improve their governing budgets more than 
others in relation to their original performance.

The distribution of wealth related to the exploitation of natural resources and commodities will also be affected. Those actors showing the least profitable industry will namely benefit most from the results of this study if applied in reality which hence also by time promotes the cosmic equity.

A situation is foreseen where man or his artificial successors travels through cosmos in the same way as the nomads on Earth of the past in full harmony with their surroundings without taking more than what they need to survive. In other terms, greed might not any longer destroy lives anymore when man explores the Universe in a similar fashion as the tribes of indigenous people that sometimes are regarded as primitive by representatives of our Western, ever more consuming but perhaps not sustainable, civilisation. In doing so, the results presented here will support the decision making of the star-fleet commanders of the future when trying to optimise their necessary ambition to exploit the natural resources in outer space in order to preserve civilisation.

Future decision makers throughout cosmos will hence on a daily basis apply the results presented here. The consequences of the theory will initially be noticed for the single entities. Valuations related to, for example, global warming and trade emissions aspects, social and equality aspects plus gender problems and so forth are less relevant due to the strictly mathematical nature of the introduced theory.

End users in space for the proposed methodology would be as follows:

- high authorities on all universal levels wanting a monitoring tool for the industrial performance and means of correction to improve the cost-effectiveness and physical impact related to the exploitation of natural and energy resources, metal and mineral commodities;

- governments wanting an investment appraisal tool to evaluate the general performance of, for example, major plants that takes into account views of the universal neighbourhood, to avoid, for example, protest actions and mass hysteria;

- governments wanting to design new survival-promoting legislation;

- courts that fix punishments related to actors' current physical impact;

- authorities wanting to apply industrial legislation in space, and;

- parties wanting to estimate and monitor the physical impact of an actor with respect to its emission and pollution levels, expressed in monetary terms.

The validity of the methods developed here is satisfactory due to the mainstream theory of business administration and economics being used as the theoretical basis for the study. The fruitful usage of the traditional economic theory in question points in this direction. The reliability of the study is acceptable due to the usage of relevant standard works and peer reviewed scientific papers that back up the outcome of the study.

Further research will study how to specifically adapt the proposed theory to the exploitation of asteroids that often are claimed to consist of many commercially valuable components. Perhaps can a technological method for "trawling fishery" of asteroids rich on strategic metals and rare minerals on Earth be developed and made fruitfully compatible with the equality principle. 
The EUROPE model may also be adapted to encompass the promising possibility to utilise the valuable water produced by geysers on moons such as the ice-covered Europa that encircles the giant gas-planet Jupiter. In the cosmic context, water is as good as gold since water is a prerequisite for life itself. Thus, it ought to be studied how to apply the equality principle also on the optimisation of water-production in space, not just for optimisation of physical matters and energy-related phenomena as is the case in this paper.

Exploitation of nutrients could also be the object of optimisation by application of the equality principle. A method cold hence be developed for how to use the EUROPE model on nutrients.

Finally, future guidelines for sustainability in space may be designed. In doing so, the basis could be the findings when applying the equality principle on the conditions in the solar system in accordance with, for example, the Gaia hypothesis, which postulates that the biosphere is a self-regulating entity with the capacity to keep our planet healthy by controlling the interconnections of the chemical and physical environment [36].

\section{CONCLUSIONS, BENEFITS AND RECOMMENDATIONS}

In this paper it is studied the economics of the exploitation of natural resources in space. The proposed theory is useful when focusing on economic and pollution-related aspects of such activities. The findings show utility for supplying Earth’s population with natural resources.

The developed methodology enables an efficient and sustainable use of natural and energy resources through the economic incentives that are provided by the present results to accomplish reduction of residuals at the source. The main features of the presented research are as follows:

1. It decreases the negative impact of residuals on the environment and the bodily health by an integrated approach to solve these problems simultaneously;

2. It provides a tool for the support of investment appraisal that can be implemented on exploitation projects which increases the economic benefits, initially at the asteroid and planetary level;

3. It enables an immediate flash-light review of mining and excavation schemes on a global and space-platform scale expressed in a single shadow cost as a key factor;

4. It generally increases the efficiency and the sustainability of the use of natural and energy resources in the present time and for the foreseeable future;

5. It increases the cost-effectiveness and equity of activities related to the exploitation of natural and energy resources and metal and mineral commodities in the cosmic context.

The over-all conclusions based on the presented theoretical findings are as follows:

1. The presented research shows a good usefulness when focusing on the cost related aspects of the management of residuals from natural resources throughout space.

2. The findings will improve the cost-effectiveness and the equity in the entire known Universe due to the proposed economic incentives leading to a better utilisation of the natural resources and a major redistribution of wealth respectively. 
The main outcomes and the major benefits from the present study are as follows:

1. Elaboration of a principle for estimation of shadow costs related to the exploitation of natural and energy resources;

2. Implication of cost-saving incentives for the interplanetary mining industry today and in the future;

3. Reduction of matter- and energy-related residuals at the source;

4. Good environmental quality due to adequate mining waste management;

5. Enhanced status of mining and excavation waste;

6. Promotion of a shift of waste management paradigms;

7. An integrated approach to solve the problem of simultaneously decreasing the negative impact of residuals on the environment and the health of the current living entities;

8. A new information support tool for decision-making in the cosmic waste management;

9. Immediate obtainment of an overall comprehension of a project's general performance by study of the proposed key figure in the form of a collocated shadow cost;

10. Good usefulness of the theoretical methodology on all kinds of commodities;

11. Theoretical findings based on well-known business administration and economics theory;

12. Good validity and reliability of the theory when implemented on the management of residuals in the universal context.

Based on the analysis performed, the following recommendations are made:

Use in space the EUROPE model, based on the equality principle, on:

1. the studying of the residuals from mining and excavation activities when deciding to invest in schemes for exploitation of natural and energy resources in order to reduce such unwanted and sometimes harmful substances;

2. the management of residuals from the exploitation of natural and energy resources in general in order to simultaneously review, monitor and evaluate a project's performance in terms of the profitability, the technological standard and the environmental conditions;

3. the industrial activities for exploitation of all kinds of commodities in order to improve the sustainability, the equity and the fairness throughout the whole sun system today and in the foreseeable future. 


\section{REFERENCES}

[1] Williams, M., 2012. The similar to 73 ka Toba super-eruption and its impact: History of a debate. Quat. Int. (258), 19-29.

[2] Bancelin, D., Hestroffer, D., Thuillot, W., 2012. Dynamics of asteroids and near-Earth objects from Gaia astrometry. Planet Space Sci. (73), 21-9.

[3] Gholipour, M., Nejad-Asghar, M., 2013. Effect of vapor pressure of grains in formation of planetesimals through the accretion disc. Astrophys. Space Sci. (344), 365-9.

[4] Dennis, D., 2011. Evil, fine-tuning and the creation of the universe. Int. J Philos. Relig. (70), 139-45.

[5] Lali, M., 2010. Analysis and design of a human spaceflight to Mars, Europa, and Titan, Space, Propulsion \& Energy Sciences International Forum Spesif - 2010. In: Book Series: AIP conference proc. (1208), 557-65.

[6] Pearson, R., 1998. Pioneer and latecomer - Comparative studies on the history of Great Britain and Germany in the age of industrialization. In: Festschrift for Sidney Pollard on his 70th birthday. Bus. Hist. (40), 181-3.

[7] Etemad, B., 2000. Europe and the colonial world. From the apogee of empires to after decolonization. Rev. Econ. (51), 257-68.

[8] European Space Agency (ESA), 2012a. http://www.esa.int, accessed may 5, 2013.

[9] National Aeronautic space Agency (NASA), 2013a. A crewed mission to Mars ... 2005. From: http://nssdc.gsfc.nasa.gov/planetary/mars/mars_crew.html, accessed January 3, 2013.

[10] National Aeronautic space Agency (NASA), 2013b. From: http://www.nasa.gov, accessed May 5, 2013.

[11] Martin, R., 1999. Money \& the Space Economy. John Wiley \& Sons, New York.

[12] Economyweb.com, 2013. Context definition of the space economy.

From: http://www.economyweb.com/space_economy.htm, accessed March 29, 2013.

[13] Rosling, H., 2010. Global population growth, box by box, TED@Cannes.

From: http://www.ted.com/talks/hans_rosling_on_global_population_growth, accessed July 4, 2014.

[14] Tilton, J. E., 2003. On borrowed time? Assessing the threat of mineral depletion. RFF Press, Washington DC.

[15] Simpson, R. D., Toman, M. A., Ayres, R. U., (Editors), 2005. Scarcity and growth revisited: Natural resources and the environment in the new millennium. RFF Press, Washington DC. 
[16] Lewis, J. S., 1997. Mining the Sky: Untold riches from the asteroids, comets, and planets. Addison-Wesley Publishing Company, New York.

[17] Glendenning, N. K., 2004. After the beginning: a cosmic journey through space and time. Imperial College Press and World Scientific Publishing Co, London.

[18] Asteroid mining, 2013. From: http://chview.nova.org/station/ast-mine.htm, accessed May 11, 2013.

[19] Theengineer.co.uk, 2013. Your questions answered: asteroid mining, April 8, 2013. From:

http://www.theengineer.co.uk/aerospace/in-depth/your-questions-answered-asteroid-mining /1015966.article, accessed May 11, 2013.

[20] Sonter, M., 1997. The technical and economic feasibility of mining the near-earth asteroids, Acta Astron. (41), 637-47.

[21] Reuters, 2012. Tech billionaires bankroll gold rush to mine asteroids. From: http://www.reuters.com/article/2012/04/24/us-space-asteroid-mining-idUSBRE83N06U201 20424, accessed May 11, 2013.

[22] CNN light years, 2012. Company aims to mine resource-rich asteroids, April 24, 2012. From: http://lightyears.blogs.cnn.com/2012/04/24/companies-plan-to-mine-precious-metals-in-spa ce/?hpt=hp_t3, accessed May 11, 2013.

[23] European Space Agency (ESA), 2012b. Esa observatory breaks world quantum teleportation record. From:

http://www.esa.int/Our_Activities/Technology/ESA_observatory_breaks_world_quantum_t eleportation_record, accessed April 27, 2013.

[24] Kluger, J., 2012. Can James Cameron - or anyone - really mine asteroids? Time Science \& Space, April 25, 2012. From:

http://www.time.com/time/health/article/0,8599,2112996,00.html?hpt=hp_c3, accessed may 11, 2013.

[25] Space.com, 2013. Asteroid mining gallery: planetary resources to mine space rocks. From: http://www.space.com/15387-asteroid-mining-planetary-resources-gallery.html, accessed May 11, 2013.

[26] Komerath, N., Nally, J., Zilin Tang, E., 2007. Policy model for space economy infrastructure. Acta Astron. (61), 1066-75.

[27] Stenis, J., 2002. Industrial Waste management models: a theoretical approach, Licentiate dissertation, Department of Construction and Architecture, Division of Construction Management, School of Engineering, Lund University, Lund, Sweden. 
[28] Stenis, J., 2005. Industrial management models with emphasis on construction waste, Doctoral thesis. Department of Construction and Architecture, Lund Institute of Technology, Lund University, Lund, Sweden, Department of Technology, University of Kalmar, Kalmar, Sweden.

[29] Moutavtchi, V., Stenis, J., Hogland, W., Shepeleva, A., 2010. Solid waste management by application of the WAMED model. J Mater. Cycles Waste Manag. (12), 169-83.

[30] Stenis, J., Moutavtchi, V., Hogland, W., 2011. Solid waste management baling scheme economics methodology. Iran J Energy \& Environ. (2), 104-16.

[31] Stenis, J., Hogland, W., 2011. Optimization of mining by application of the equality principle. Resour. Policy (36), 285-92.

[32] National Aeronautic space Agency (NASA), 2013c. Robotic asteroid prospector (RAP) Staged from L-1: Start of the Deep Space Economy.

From: http://www.nasa.gov/directorates/spacetech/niac/2012_phase_I_fellows_cohen.html, accessed May 11, 2013.

[33] Massonnet, D., Meyssignac, B., 2006. A captured asteroid: Our David's stone for shielding earth and providing the cheapest extraterrestrial material. Acta Astron. (59), 77-83.

[34] OECD, 2011. Gross domestic product (GDP) for the United States 2007-11. From: http://stats.oecd.org/Index.aspx?DataSetCode=SNA_TABLE1, accessed May 15, 2013.

[35] Gertsch, R. L., Gertsch, L., 1997. Economic analysis tools for mineral projects in space, Space Resources Roundtable.

From: http://www.kemcom.net/EconAnal.pdf, accessed May 11, 2013.

[36] Ball, P., 2014. James Lovelock reflects on Gaia's legacy. Nature. Doi:10.1038/nature.2014.15017. 